\title{
Elevated brain natriuretic peptide predicts mortality in interstitial lung disease
}

\author{
T.J. Corte*\#, S.J. Wort*,, M.A. Gatzoulis*,", R. Engel*, G. Giannakoulas*, \\ P.M. Macdonald ${ }^{\#}$ and A.U. Wells*"
}

ABSTRACT: Elevated pulmonary vascular resistance portends a poor prognosis across interstitial lung disease (ILD), irrespective of the histospecific diagnosis. Currently, no noninvasive surrogate prognostic marker exists. We explore the prognostic value of brain natriuretic peptide (BNP) and echocardiography across ILD.

ILD patients with BNP concentrations performed during 2005-2007 were reviewed $(n=90)$. Echocardiography tapes were reviewed by a cardiologist blinded to other results. Outcome was evaluated for survival against BNP and echocardiograph parameters. A priori threshold values and composite markers were evaluated against survival.

During follow-up ( $20 \pm 9$ months) there were 28 deaths (31\%). BNP correlated with right heart echocardiographic indices, including right ventricular systolic pressure (RVSP) $\left(R^{2}=0.18\right.$, $p=0.0002)$ but not with parameters of left heart function. Nonsurvivors had higher BNP and RVSP levels than survivors. BNP $\geqslant 20 \mathrm{pmol} \cdot \mathrm{L}^{-1}$ (hazard ratio (HR) $2.93,95 \% \mathrm{Cl} 1.28-6.73 ; p=0.01$ ) and moderate-severe pulmonary hypertension (HR 2.53, 95\% Cl 1.15-5.57; $\mathrm{p}=0.02$ ) were associated with increased mortality, independent of age, sex and pulmonary function. Patients with $\mathrm{BNP} \geqslant 20 \mathrm{pmol} \cdot \mathrm{L}^{-1}$ had a 14-fold increased mortality over those with $\mathrm{BNP}<4 \mathrm{pmol} \cdot \mathrm{L}^{-1}$.

Increased BNP levels and/or echocardiographic markers of right ventricular dysfunction were associated with increased mortality across ILD. The link between vascular parameters and mortality supports the concept that pulmonary vascular disease contributes to the final common pathway seen across ILD.

KEYWORDS: Brain natriuretic peptide, echocardiogram, interstitial lung disease, prognosis, pulmonary hypertension, right ventricular function

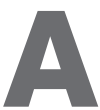
cross interstitial lung disease (ILD), survival is universally poor when pulmonary hypertension $(\mathrm{PH})$ is present [1-3]. We have recently demonstrated that elevated pulmonary vascular resistance measured by right heart catheter (RHC) strongly predicts rapid mortality across ILD patients [4]. However, RHC is moderately invasive, and not always practicable. Surrogate noninvasive markers of pulmonary vascular compromise are, therefore, highly desirable in this setting. We explore the prognostic significance of brain natriuretic peptide (BNP) and echocardiographic parameters of right ventricular (RV) dysfunction in ILD patients, with reference to both overall and short-term mortality.

$\mathrm{PH}$ is not uncommon in patients with ILD, with reported prevalence amongst patients with idiopathic pulmonary fibrosis (IPF) ranging 32-85\% $[3,5-10]$. $\mathrm{PH}$ is more common in patients with severe fibrosis $[7,11]$, but may develop at any stage of the disease process [2, 12, 13]. In the subgroup of patients with mild underlying fibrosis and poorer prognoses, the poor outcome may be attributed in part to microvascular compromise and subsequent development of PH. Having recently shown that pulmonary vascular resistance is a strong predictor of mortality in advanced ILD [4], we now explore prognostic markers of vascular impairment across a wider range of disease severity.

$\mathrm{BNP}$, a peptide secreted in response to ventricular stretch by the cardiomyocytes of both the right and left ventricles [14], is an important marker of RV dysfunction [15, 16]. BNP concentrations correlate well with RHC parameters in patients with idiopathic pulmonary arterial hypertension (PAH) and $\mathrm{PH}$ associated with chronic lung disease, in which elevated BNP concentrations are associated with a poorer functional capacity and prognosis [17, 18]. In IPF, a study of 39 patients showed that BNP
AFFILIATIONS

*Royal Brompton Hospital and National Heart and Lung Institute, and "Imperial College, London, UK. \#University of New South Wales, Sydney, Australia.

CORRESPONDENCE

A.U. Wells

Interstitial Lung Disease Unit

Royal Brompton Hospital and National Heart and Lung Institute Imperial College

Emmanuel Kaye Building

1B Manresa Road

London

SW3 6LP

UK

E-mail: athol.wells@rbht.nhs.uk

Received:

Nov 022009

Accepted after revision:

Feb 252010

First published online:

March 112010 
performed well in the identification of $\mathrm{PH}$ [19]. A recent IPF study has identified BNP as a marker for poor prognosis (particularly when combined with echocardiographic data) [20].

We hypothesise that markers of RV dysfunction may be identifiable prior to development of overt PH. Furthermore, such markers may be useful in predicting survival. Thus, the goal of this study was to explore the prognostic value of vascular markers (including BNP and echocardiography) across ILD patients.

\section{METHODS}

\section{Patient selection}

Plasma BNP was introduced at our institution in 2005, and thereafter performed routinely in all new ILD referrals and in ILD patients being investigated for PH. ILD patients with plasma BNP concentrations performed from 2005 to December $2007(n=90)$ were identified from the hospital database. Hospital records were reviewed and demographic and clinical data were recorded.

Patients were followed to death, transplantation, last clinic follow-up or February 1, 2009. Five patients were lost to followup, two underwent pulmonary transplantation and 28 (31\%) of patients died during the follow-up period ( $20 \pm 9$ months).

\section{A priori thresholds}

As described in our study of severe interstitial disease [4], we studied vascular markers as continuous variables, and according to a priori thresholds: 1) $\mathrm{BNP} \geqslant 4 \mathrm{pmol} \cdot \mathrm{L}^{-1}$ and $\geqslant 20 \mathrm{pmol} \cdot \mathrm{L}^{-1}$ [20]; and 2) echocardiographic evidence of $\mathrm{PH}$ (right ventricular systolic pressure (RVSP) $\geqslant 40 \mathrm{mmHg}$ or right heart dilatation) and moderate-severe $\mathrm{PH}$ (RVSP $\geqslant 50 \mathrm{mmHg}$ or right heart dilatation) [12].

\section{Investigations}

\section{Brain natriuretic peptide}

Venous blood samples were collected for BNP testing into tubes containing potassium EDTA. The BNP samples were analysed within $4 \mathrm{~h}$ or, in some cases, whole blood was centrifuged and the plasma stored at $-80^{\circ} \mathrm{C}$ until analysis [21, 22]. The BNP concentrations were quantified using the Beckman Access 2, Triage BNP assay (Biosite Diagnostics Inc., San Diego, CA, USA). This BNP assay is a sandwich immunoassay consisting of a disposable device to which $250 \mu \mathrm{L}$ of EDTA-anticoagulated whole blood or plasma is added. Cells are separated from plasma by a filter, and the plasma (containing BNP) is incubated for $\sim 2 \mathrm{~min}$ in a reaction chamber containing fluorescent-tagged BNP antibodies. Finally, the plasma is directed by capillary action to an area of immobilised antibody that binds the BNP-fluorescent antibody complex, and the remaining fluid is washed away. After $15 \mathrm{~min}$, the device is placed in the triage meter, the intensity of the fluorescent signal is measured and the BNP concentration calculated by the triage meter from an internal calibration curve.

Normal values are $<4 \mathrm{pmol} \cdot \mathrm{L}^{-1}$. Age- and sex-adjusted values are not available for this assay, and so, adjustments for age and sex were performed for each analysis. Thus, we examined BNP $\geqslant 4 \mathrm{pmol} \cdot \mathrm{L}^{-1}$ and $\geqslant 20 \mathrm{pmol} \cdot \mathrm{L}^{-1}$ as a priori thresholds (corresponding to one and five times the upper limit of normal) [20].
When multiple BNP levels were available, the BNP concentration closest to echocardiography was employed for analysis.

\section{Echocardiography}

All patients underwent two-dimensional echocardiography using Doppler and colour flow imaging (median time (range) from BNP 1 (0-10) months. Right atrial pressure (RAP) was estimated on the basis of inferior vena cava size and movement on respiration [23]. RVSP was calculated as the sum of tricuspid peak gradient (based on the modified Bernoulli equation) [24] and RAP. Pulmonary artery flow velocity was recorded, and pulmonary acceleration time (PAT) was measured as the interval between its onset and peak velocity point. Right atrial dilation, RV dilation and RV dysfunction were scored as present or absent.

All echocardiographic studies were reviewed by an independent and senior operator, who was blinded to patients' clinical characteristics and the results of other investigations. Specific predetermined right and left ventricular indices were recorded. PH was considered present when RVSP was $\geqslant 40 \mathrm{mmHg}$ or there was right heart dilatation. Moderatesevere $\mathrm{PH}$ was defined as RVSP $\geqslant 50 \mathrm{mmHg}$ or right heart dilatation.

\section{Other investigations}

Pulmonary function testing was performed in all patients (median time (range) from BNP 1 (0-30) months), and predicted values were calculated according to the American Thoracic Society (ATS) and the European Respiratory Society (ERS) guidelines (Jaeger Masterscreen; Cardinal Health UK 240 Ltd, Warwick, UK) [25-28]. Lung volumes (constant volume body plethysmograph), spirometric volumes and single-breath diffusion capacity of the lung for carbon monoxide $(D \mathrm{~L}, \mathrm{CO})$ were measured. The composite physiologic index (CPI) was calculated according to the following formula [29]:

$\mathrm{CPI}=91-0.65 \times(\mathrm{DL}, \mathrm{CO} \%)-0.53 \times(\mathrm{FVC} \%)+0.34 \times(\mathrm{FEV} 1 \%)$ in which FVC is the forced vital capacity and FEV1 is the forced expiratory volume in $1 \mathrm{~s}$.

End capillary (ear-lobe) blood gas analysis was performed on room air $(n=74)$.

A 6-min walk test (6MWT) was performed in 55 patients, (median time (range) from BNP 1.4 (0-31) months) was performed by senior personnel in accordance with ATS/ERS guidelines [30] with standardised verbal prompts. The 6MWT was performed on room air or oxygen $(n=10)$ if patients were receiving continuous supplemental oxygen.

\section{Statistical analysis}

All analyses were performed using STATA statistical software (version 10.0; Stata Corp., College Station, TX, USA). Data are expressed as mean \pm SD or as median (range), as appropriate. Group comparisons were made using unpaired t-test or Wilcoxon's rank-sum test.

Outcome was evaluated for overall mortality (Cox regression, with satisfaction of the assumptions of proportional hazards analysis) and death within the first year (logistic regression). Covariates included BNP and the RVSP as continuous variables, as well as the a priori thresholds described previously. 
Multivariate survival analysis was performed, adjusting for age, sex, CPI, duration of dyspnoea [31] and creatinine levels. Analysis was repeated with the exclusion of each diagnostic subgroup [4]. Kaplan-Meier curves were generated for categorical variables, and the log-rank test was used to identify significant differences between categories.

Univariate relationships were examined using Pearson's or Spearman's rank correlation test, as appropriate. BNP thresholds were evaluated against the presence of $\mathrm{PH}$ and moderatesevere $\mathrm{PH}$ with the Chi-squared test. $\mathrm{p}$-values $<0.05$ were regarded as statistically significant throughout.

\section{RESULTS}

\section{Patient characteristics}

90 patients (age 59 12 yrs; 47 (52\%) males) fulfilled entry criteria. ILD diagnoses included: IPF $(n=16)$, idiopathic nonspecific interstitial pneumonia (computed tomography diagnosis; $n=21$ ), connective tissue disease-related fibrosis $(n=18)$, sarcoidosis $(n=11)$, chronic hypersensitivity pneumonia $(n=9)$, smoking-related interstitial lung disease $(n=8)$, drug-related interstitial fibrosis $(n=2)$ and other ILD $(n=5) .43$ patients were life-long nonsmokers, 39 were ex-smokers and five were current smokers (three unknown; mean $\pm \mathrm{SD}$ $25.5 \pm 16.6$ pack-yrs). 13 patients $(14 \%)$ had a history of cardiac disease. At the time of assessment closest to the BNP assay, the

\begin{tabular}{|c|c|c|c|}
\hline TABLE 1 & Entire group & Survivors & Nonsurvivors \\
\hline Subjects & $90(100)$ & $62(69)$ & $28(31)$ \\
\hline Age yrs & $59 \pm 12$ & $58 \pm 14$ & $58 \pm 15$ \\
\hline Males & $47(52)$ & $29(47)$ & $18(64)$ \\
\hline Creatinine $\mu \mathrm{mol} \cdot \mathrm{L}^{-1}$ & $88.5 \pm 26.2$ & $87.7 \pm 26.0$ & $91.9 \pm 27.3$ \\
\hline \multicolumn{4}{|l|}{ Pulmonary function } \\
\hline$D \mathrm{~L}, \mathrm{CO} \%$ pred & $38.0 \pm 15.9$ & $39.7 \pm 16.6$ & $34.0 \pm 13.7$ \\
\hline FVC \% pred & $75.3 \pm 22.3$ & $78.6 \pm 21.9 *$ & $68.1 \pm 21.7^{\star}$ \\
\hline TLC \% pred & $77.1 \pm 19.8$ & $79.3 \pm 20.2$ & $71.7 \pm 18.1$ \\
\hline $\mathrm{Pa}, \mathrm{O}_{2} \mathrm{kPa}$ & $9.2 \pm 2.3$ & $9.5 \pm 2.9$ & $8.5 \pm 2.0$ \\
\hline \multicolumn{4}{|l|}{ 6-min walk test ${ }^{\#}$} \\
\hline End test $\mathrm{Sp}, \mathrm{O}_{2} \%$ & $83.3 \pm 8.8$ & $84.2 \pm 9.1$ & $82.5 \pm 9.3$ \\
\hline 6-min walk distance m & $271 \pm 127$ & $277 \pm 130$ & $258 \pm 123$ \\
\hline $\begin{array}{l}\text { Brain natriuretic peptide } \\
\mathrm{pmol} \cdot \mathrm{L}^{-1}\end{array}$ & $11(1.4-377)$ & $9(3-193.8)^{\bullet}$ & $22(1.4-377)^{\bullet}$ \\
\hline \multicolumn{4}{|l|}{ Echocardiography } \\
\hline RVSP $\mathrm{mmHg}^{+}$ & $49.9 \pm 21.7$ & $46.9 \pm 21.3^{\star}$ & $59.2 \pm 19.1^{\star}$ \\
\hline $\mathrm{RAP} \mathrm{mmHg}$ & $8.3 \pm 3.9$ & $8.0 \pm 4.1$ & $8.8 \pm 3.4$ \\
\hline $\begin{array}{l}\text { Pulmonary acceleration } \\
\text { time ms }\end{array}$ & $96.8 \pm 26.9$ & $109.3 \pm 32.3$ & $102.2 \pm 31.2$ \\
\hline Fractional shortening \% & $36.8 \pm 9.2$ & $37.6 \pm 9.8$ & $35.1 \pm 7.9$ \\
\hline \multicolumn{4}{|c|}{ 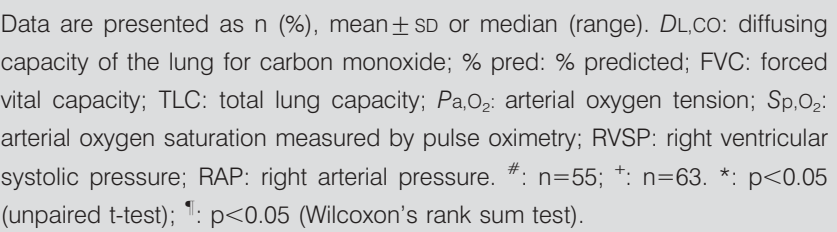 } \\
\hline
\end{tabular}

median duration of dyspnoea was 24 (0-192) months and World Health Organization functional class was 2 (1-4).

$79(88 \%)$ had BNP $\geqslant 4 \mathrm{pmol} \cdot \mathrm{L}^{-1}$ and 38 (39\%) had BNP $\geqslant 20 \mathrm{pmol} \cdot \mathrm{L}^{-1}$. On echocardiography, $\mathrm{PH}$ was evident in 53 $(59 \%)$, and moderate-severe PH in $39(43 \%)$ of patients. Seven patients had evidence of left ventricular failure (mean fractional shortening $36.7 \pm 9 \%)$. On $6 \mathrm{MWT}, 39$ patients $(42 \%)$ had oxygen desaturation $<88 \%$. $13(14 \%)$ patients had elevated creatinine concentrations $\left(>120 \mu \mathrm{mol} \cdot \mathrm{L}^{-1}\right)$. Other baseline parameters are summarised in table 1.

\section{BNP correlations with echocardiography}

BNP concentration correlated with echocardiographic indices of right heart function, including $\operatorname{RVSP}\left(\mathrm{R}^{2}=0.18, \mathrm{p}=0.0002\right)$ and PAT $\left(R^{2}=0.11, p=0.002\right)$, but the relationships were weak (all $\mathrm{R}^{2}$ values $<0.20$ ). BNP also correlated with $D \mathrm{~L}, \mathrm{CO} \%$ pred, transfer coefficient of the lung carbon monoxide, arterial oxygen tension measured by pulse oximetry, arterial oxygen tension and the 6MWT distance. BNP did not correlate with echocardiographic parameters of left heart function (table 2). $\mathrm{BNP} \geqslant 20 \mathrm{pmol} \cdot \mathrm{L}^{-1}$ was associated with moderate-severe $\mathrm{PH}$ on echocardiography $(\mathrm{p}<0.0001)$.

\begin{tabular}{|c|c|c|c|}
\hline Baseline parameters & Subjects $n$ & $\mathbf{R}^{\#}$ & p-value \\
\hline Age yrs & 90 & 0.50 & $<0.00001$ \\
\hline WHO class & 90 & 0.33 & 0.002 \\
\hline \multicolumn{4}{|l|}{ Pulmonary function } \\
\hline$D \mathrm{~L}, \mathrm{CO} \%$ & 89 & -0.29 & 0.006 \\
\hline FVC \% & 86 & 0.14 & 0.19 \\
\hline $\mathrm{Pa}, \mathrm{O}_{2} \mathrm{kPa}$ & 74 & -0.22 & $<0.05$ \\
\hline \multicolumn{4}{|l|}{ 6-min walk test } \\
\hline End-test $\mathrm{Sp}, \mathrm{O}_{2} \%$ & 55 & -0.003 & 0.98 \\
\hline Distance m & 55 & -0.35 & 0.009 \\
\hline \multicolumn{4}{|l|}{ Echocardiography right heart indices } \\
\hline RVSP mmHg & 64 & 0.43 & 0.0002 \\
\hline Peak tricuspid velocity $\mathrm{m} \cdot \mathrm{s}^{-1}$ & 64 & 0.39 & 0.02 \\
\hline $\begin{array}{l}\text { Degree of tricuspid regurgitation } \\
\text { (scale 1-4) }\end{array}$ & 90 & 0.34 & 0.0008 \\
\hline Right atrial pressure $\mathrm{mmHg}$ & 78 & 0.27 & 0.02 \\
\hline Right atrial area $\mathrm{cm}^{2}$ & 87 & 0.42 & $<0.00001$ \\
\hline $\begin{array}{l}\text { Longitudinal motion at tricuspid valve } \\
\text { annulus } \mathrm{cm}\end{array}$ & 84 & -0.29 & 0.008 \\
\hline Right ventricular inlet diameter $\mathrm{cm}$ & 88 & 0.36 & 0.0004 \\
\hline Pulmonary acceleration time ms & 88 & -0.33 & 0.002 \\
\hline \multicolumn{4}{|l|}{ Echocardiography left heart indices } \\
\hline Left atrial area $\mathrm{cm}^{2}$ & 88 & 0.02 & 0.84 \\
\hline Left ventricular end systolic diameter $\mathrm{cm}$ & 90 & 0.11 & 0.32 \\
\hline $\begin{array}{l}\text { Longitudinal motion at mitral valve } \\
\text { annulus } \mathrm{cm}\end{array}$ & 87 & -0.20 & 0.07 \\
\hline Fractional shortening \% & 87 & -0.12 & 0.26 \\
\hline
\end{tabular}

DL,CO: diffusing capacity of the lung for carbon monoxide; FVC: forced vital capacity; $\mathrm{Pa}_{2} \mathrm{O}_{2}$ : arterial oxygen tension; $\mathrm{Sp}, \mathrm{O}_{2}$ : arterial oxygen saturation measured by pulse oximetry; RVSP: right ventricular systolic pressure. \#: Spearman's rank correlation coefficient. 


\section{Characteristics of survivors and nonsurvivors}

During the follow-up period of $20 \pm 9$ months, there were 28 (31\%) deaths. Nonsurvivors had higher BNP and RVSP levels and lower FVC \% predicted levels than survivors (table 1). Nonsurvivors were more likely to have BNP concentration $\geqslant 20 \mathrm{pmol} \cdot \mathrm{L}^{-1}$ ( 15 out of 28 versus 15 out of $62 ; \mathrm{p}=0.006$ ) and to have moderate-severe PH (17 out of 28 versus 22 out of 62; $\mathrm{p}=0.03$ ) than survivors.

\section{Survival analysis}

Brain natriuretic peptide

Higher BNP concentrations were associated with increased mortality (HR 1.00, 95\% CI 1.00-1.01; $\mathrm{p}=0.004$ ) independent of age, sex and pulmonary function. BNP $\geqslant 4 \mathrm{pmol} \cdot \mathrm{L}^{-1}$ was not associated with survival. However, patients with BNP $\geqslant 20 \mathrm{pmol} \cdot \mathrm{L}^{-1}$ had higher mortality (HR 2.93, 95\% CI 1.286.73; $\mathrm{p}=0.01)$ than those with $\mathrm{BNP}<20 \mathrm{pmol} \cdot \mathrm{L}^{-1}$, independent of age, sex and pulmonary function (fig. 1a). 1-yr mortality for patients with $\mathrm{BNP} \geqslant 20 \mathrm{pmol} \cdot \mathrm{L}^{-1}$ was $28.5 \%$ compared with $10.1 \%$ for those with BNP $<20 \mathrm{pmol} \cdot \mathrm{L}^{-1}(\mathrm{p}=0.009)$. Patients with $\mathrm{BNP} \geqslant 20 \mathrm{pmol} \cdot \mathrm{L}^{-1}$ had a 14 -fold increase in mortality over patients with $\mathrm{BNP}<4 \mathrm{pmol} \cdot \mathrm{L}^{-1}$ independent of age, sex and pulmonary function (HR 13.92, 95\% CI 1.52-128.79; $\mathrm{p}=0.02$; table 3 ). However, there was no significant difference in mortality between patients with BNP $4-20 \mathrm{pmol} \cdot \mathrm{L}^{-1}$ and $<4 \mathrm{pmol} \cdot \mathrm{L}^{-1}$. These findings remained significant following adjustment for serum creatinine concentration and duration of dyspnoea, and with the exclusion of each diagnostic subgroup in turn, in separate models, indicating that the overall trends were not overly influenced by one single subgroup.

\section{Pulmonary hypertension}

RVSP was associated with survival (HR 1.03, 95\% CI 1.00-1.05; $\mathrm{p}=0.02$ ) following adjustment for age, sex and pulmonary function. The presence of $\mathrm{PH}$ on echocardiography was not significantly associated with survival (table 3 ). However, those with moderate-severe $\mathrm{PH}$ had a higher mortality (HR 2.53, 95\% CI 1.15-5.57; $\mathrm{p}=0.02)$ independent of age, sex and pulmonary function (table 3 ; fig. 1b). The 1-yr mortality rate for patients with moderate-severe $\mathrm{PH}$ was $20.7 \%$ compared to $12.0 \%$ for those without moderate-severe PH $(\mathrm{p}=0.03)$.

\section{BNP combined with echocardiography}

Patients with $\mathrm{BNP} \geqslant 20 \mathrm{pmol} \cdot \mathrm{L}^{-1}$ and moderate-severe $\mathrm{PH}$ on echocardiography had higher mortality (HR 2.93, 95\% CI 1.406.20; $p=0.005)$ than patients without both these findings. However, the prognostic distinction of these parameters in combination was no stronger than the simple distinction made from the threshold of $\mathrm{BNP} \geqslant 20 \mathrm{pmol} \cdot \mathrm{L}^{-1}$ alone. Furthermore, in patients with $\mathrm{BNP}<20 \mathrm{pmol} \cdot \mathrm{L}^{-1}$, mortality was no higher if there was moderate-severe $\mathrm{PH}$ on echocardiography $(\mathrm{p}=0.58)$.

Patients with $\mathrm{BNP} \geqslant 20 \mathrm{pmol} \cdot \mathrm{L}^{-1}$ had lower $\mathrm{DL}, \mathrm{CO} \%, 6 \mathrm{MWT}$ distance, PAT and higher RVSP and RAP (table 4).

\section{DISCUSSION}

The results of the current study demonstrate the prognostic value of BNP and echocardiography over the ILD population as a whole, independent of underlying disease severity. Elevated BNP concentration and RVSP levels were linked to increased mortality across ILD. When evaluated as a continuous variable, increased serum BNP concentration was the strongest predictor of overall mortality. Unlike pulmonary vascular resistance, which predicts early death [4], elevated BNP and RVSP were predictive of overall, but not short-term, mortality. This suggests that while elevated pulmonary vascular resistance is a marker of end-stage $\mathrm{PH}, \mathrm{BNP}$ and echocardiography reflect earlier pulmonary vascular disease.

BNP concentration, as a continuous variable, was the strongest predictor of overall mortality across the ILD population. This finding is in keeping with observations in a recent IPF study [20]. It is not surprising that elevated BNP levels are associated with increased mortality, as both BNP and the more stable $\mathrm{N}$-terminal pro-BNP are known to be prognostic markers in idiopathic PAH [17, 32-34] and chronic lung disease [18].

We considered it important to establish whether dichotomous BNP values, above and below a priori threshold values, provided equivalent prognostic utility to continuous BNP values. Patients with BNP levels above the threshold of $20 \mathrm{pmol} \cdot \mathrm{L}^{-1}$ had a three-fold increase in mortality over those with $\mathrm{BNP}<20 \mathrm{pmol} \cdot \mathrm{L}^{-1}$ and a 14 -fold increase in mortality above those with $\mathrm{BNP}<4 \mathrm{pmol} \cdot \mathrm{L}^{-1}$. However, when BNP was
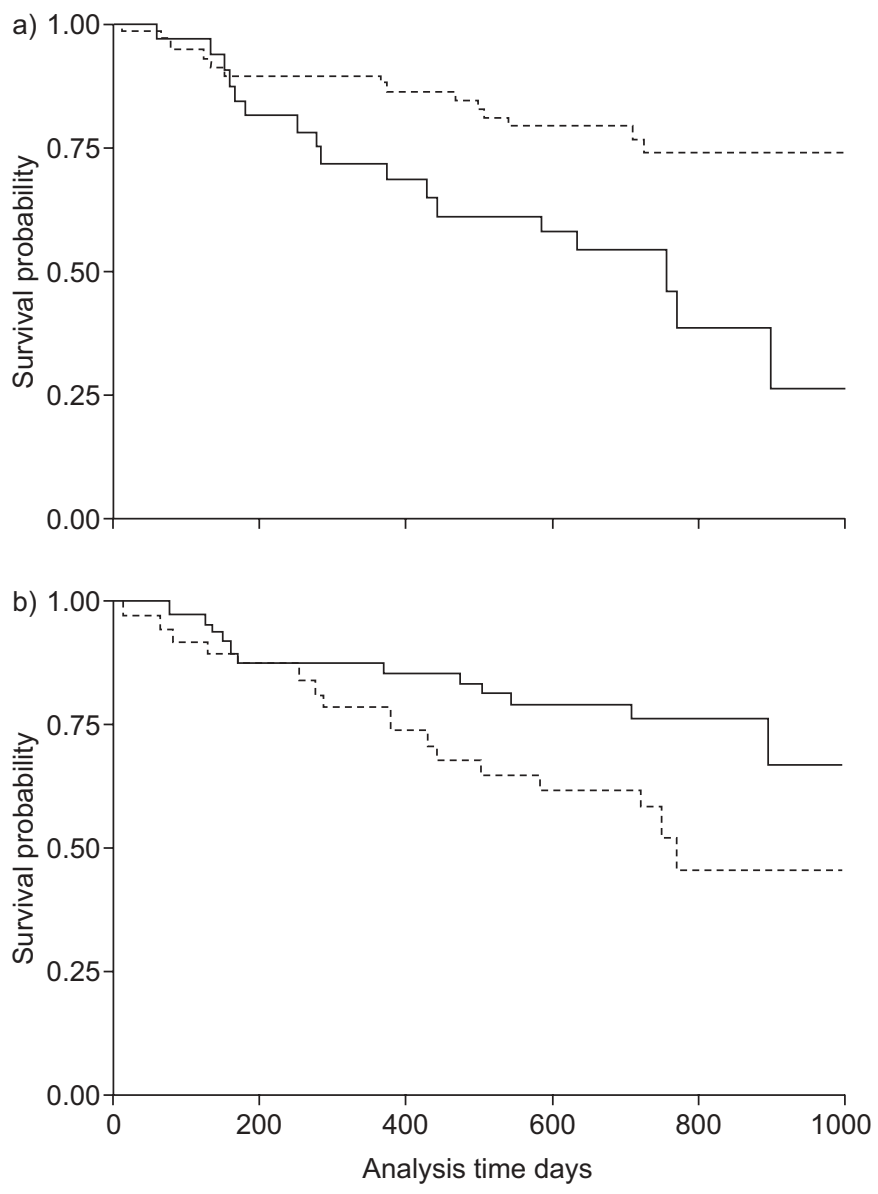

FIGURE 1. Kaplan-Meier survival curve for a) brain natriuretic peptide (BNP) $\geqslant 20 \mathrm{pmol} \cdot \mathrm{L}^{-1}\left({ }^{-}-\right.$- : BNP $<20 \mathrm{pmol} \cdot \mathrm{L}^{-1} ;$ — $\left.\mathrm{BNP}>20 \mathrm{pmol} \cdot \mathrm{L}^{-1}\right)$ and $\left.\mathrm{b}\right)$ moderate-severe pulmonary hypertension $(\mathrm{PH})(----$ : with moderate-severe $\mathrm{PH}$; - : without moderate-severe $\mathrm{PH})$. Patients with $\mathrm{BNP} \geqslant 20 \mathrm{pmol} \cdot \mathrm{L}^{-1}(p=0.009)$ and moderate-severe $\mathrm{PH}(\mathrm{p}=0.03)$ had poorer survival than those with BNP $<20 \mathrm{pmol} \cdot \mathrm{L}^{-1}$ and without moderate-severe $\mathrm{PH}$, respectively. 
TABLE 3 Overall and 1-yr survival (for continuous variables and a priori thresholds of brain natriuretic peptide (BNP) and right ventricular systolic pressure (RVSP))

\begin{tabular}{|c|c|c|c|c|}
\hline & \multicolumn{2}{|c|}{ Overall survival $^{\#}$} & \multicolumn{2}{|l|}{ 1-yr survival } \\
\hline & HR (95\% Cl) & p-value & OR $(95 \% \mathrm{Cl})$ & p-value \\
\hline \multicolumn{5}{|l|}{ BNP } \\
\hline BNP continuous $\mathrm{pmol} \cdot \mathrm{L}^{-1}$ & $1.01(1.00-1.01)$ & $0.004^{\# \#}$ & $1.00(0.996-1.01)$ & 0.35 \\
\hline BNP 4-20 pmol. $\mathrm{L}^{-1 \S}$ & $2.95(0.35-24.64)$ & 0.32 & & \\
\hline $\mathrm{BNP} \geqslant 20 \mathrm{pmol} \cdot \mathrm{L}^{-1 \S}$ & $13.92(1.52-127.79)$ & $0.02^{\# \#}$ & $\begin{array}{l}\text { No deaths in } 1 \mathrm{yr} \text { in patients } \\
\text { with } \mathrm{BNP}<4 \mathrm{pmol} \cdot \mathrm{L}^{-1}\end{array}$ & \\
\hline \multicolumn{5}{|l|}{ Echocardiography } \\
\hline RVSP continuous $\mathrm{mmHg}^{f}$ & $1.03(1.00-1.05)$ & $0.04^{\# \#}$ & $1.01(0.98-1.06)$ & 0.37 \\
\hline Echocardiography $\mathrm{PH}$ & $1.99(0.84-4.71)$ & 0.12 & $2.64(0.62-11.36)$ & 0.19 \\
\hline Echocardiography moderate-severe $\mathrm{PH}$ & $2.53(1.15-5.57)$ & $0.02^{\# \#}$ & $2.18(0.59-8.09)$ & 0.24 \\
\hline \multicolumn{5}{|l|}{ Composite markers } \\
\hline $\mathrm{BNP} \geqslant 20 \mathrm{pmol} \cdot \mathrm{L}^{-1}$ and echocardiography moderate-severe $\mathrm{PH}$ & $3.18(1.37-7.43)$ & $0.007^{\# \#}$ & $2.89(0.68-12.2)$ & 0.15 \\
\hline
\end{tabular}

$\mathrm{PH}$ : pulmonary hypertension. ${ }^{\#}$ : Cox regression analysis was used for overall survival analysis (adjusted for age, sex and composite physiologic index); ${ }^{\natural}$ : logistic regression was used for 1-yr survival analysis (adjusted for age, sex and composite physiologic index); ${ }^{\text {s: }}$ compared with patients with normal BNP concentrations (BNP $<4$ pmol. $\left.L^{-1}\right) ; f: n=64 ;{ }^{\# \#}$ : results remained significant following adjustment for serum creatinine concentration $\left(\mu \mathrm{mol} \cdot \mathrm{L}^{-1}\right)$ and duration of dyspnoea (months).

considered as a dichotomous variable, it provided no additional prognostic information over echocardiography. Thus, on the basis of the current study, we cannot recommend a useful threshold BNP level for a prognostic clinical algorithm. However, patient numbers above and below

\begin{tabular}{|c|c|c|c|}
\hline \multirow[t]{2}{*}{ TABLE 4} & \multicolumn{3}{|c|}{$\begin{array}{l}\text { Baseline parameters characterised by brain } \\
\text { natriuretic peptide }(B N P) \geqslant 20 \mathrm{pmol} \cdot \mathrm{L}^{-1} \text { and } \mathrm{BNP} \\
<20 \mathrm{pmol} \cdot \mathrm{L}^{-1}\end{array}$} \\
\hline & & $\mathrm{BNP} \geqslant 20 \mathrm{pmol} \cdot \mathrm{L}^{-1}$ & BNP $<20 \mathrm{pmol} \cdot \mathrm{L}^{-1}$ \\
\hline Subjects & & $30(33)$ & $60(67)$ \\
\hline Age yrs & & $64 \pm 11^{*}$ & $56 \pm 12^{*}$ \\
\hline Males & & $18(30)$ & $29(60)$ \\
\hline \multicolumn{4}{|c|}{ Pulmonary function } \\
\hline$D \mathrm{~L}, \mathrm{CO} \%$ pre & & $32.0 \pm 14.8^{\star}$ & $40.8 \pm 15.8^{*}$ \\
\hline FVC $\%$ pred & & $78.0 \pm 24.3$ & $73.9 \pm 21.3$ \\
\hline TLC \% pred & & $79.3 \pm 17.6$ & $76.0 \pm 20.8$ \\
\hline $\mathrm{Pa}_{1} \mathrm{O}_{2} \mathrm{kPa}$ & & $8.6 \pm 2.7$ & $9.5 \pm 2.1$ \\
\hline \multicolumn{4}{|c|}{$6-\mathrm{min}$ walk test ${ }^{\#}$} \\
\hline End test $\mathrm{Sp}$ & $\mathrm{O}_{2} \%$ & $84.0 \pm 8.9$ & $83.4 \pm 9.4$ \\
\hline 6-min walk c & istance $\mathrm{m}$ & $214 \pm 126^{\star}$ & $310 \pm 113^{*}$ \\
\hline \multicolumn{4}{|c|}{ Echocardiography } \\
\hline RVSP $\mathrm{mmH}$ & & $61.8 \pm 25.8^{\star}$ & $42.0 \pm 14.0^{*}$ \\
\hline RAP $\mathrm{mmHg}$ & & $10.2 \pm 0.9^{\star}$ & $7.3 \pm 2.7^{\star}$ \\
\hline Pulmonary a & cceleration time ms & $86.2 \pm 21.8^{*}$ & $102.1 \pm 27.8^{*}$ \\
\hline Fractional sł & ortening \% & $36.1 \pm 9.3$ & $37.2 \pm 9.3$ \\
\hline
\end{tabular}

Data are presented as $n(\%)$ or mean \pm SD. DL,CO: diffusing capacity of the lung for carbon monoxide; \% pred: \% predicted; FVC: forced vital capacity; TLC: total lung capacity; $\mathrm{Pa}_{\mathrm{a}} \mathrm{O}_{2}$ : arterial oxygen tension; $\mathrm{Sp}, \mathrm{O}_{2}$ : arterial oxygen saturation measured by pulse oximetry; RVSP: right ventricular systolic pressure; RAP: right arterial pressure. ${ }^{*}: \mathrm{n}=55$. ${ }^{*}: \mathrm{p}<0.05$ between groups (unpaired t-test). threshold values were small, and larger studies are warranted to further explore this hypothesis before the combination of BNP and echocardiography is dismissed as a potential surrogate prognostic index.

Our results suggest that the clinical utility of serum BNP lies primarily in its superior prediction of mortality when used as a continuous variable. This indicates that the advantage of BNP lies not in defining the presence of pulmonary vascular involvement, using dichotomous threshold values, but in quantifying the degree of pulmonary vascular involvement across the whole spectrum of disease severity. Our results strongly justify the exploration of BNP as a continuous variable in the future formulation of composite prognostic indices.

In contrast to BNP concentrations, RVSP had equivalent prognostic value, whether considered as a dichotomous or continuous variable. Moderate to severe $\mathrm{PH}$ on echocardiography was associated with a three-fold increase in mortality, independent of the severity of the underlying ILD. This finding is consistent with previous echocardiography studies in IPF [1].

In advanced ILD there appears to be a final common pathway across the spectrum of ILD disorders. In one study, survival did not differ between biopsy-proven IPF and nonspecific interstitial pneumonia in patients with $D$ L,CO levels $<35 \%$ pred [35]. In another report, patients with severe hypersensitivity pneumonitis had an outcome similar to that of IPF [36]. We suggest that pulmonary vasculopathy may contribute to this final common pathway across the ILD population. In support of this hypothesis, we have recently demonstrated that elevated pulmonary vascular resistance is a marker for early death across the spectrum of ILD patients [4]. Moreover, in the current study we show that elevated BNP levels and echocardiographic parameters of $\mathrm{PH}$, both markers of vascular stress, were indeed linked to increased mortality across ILD 
independent of the severity of underlying lung disease. These results support the concept that pulmonary vasculopathy has important prognostic implications across ILD, and may contribute to the final common pathway in ILD patients.

\section{BNP as a marker of RV dysfunction}

In the current study, we show significant, albeit weak, positive correlations between BNP and markers of RV dysfunction. BNP levels $>20 \mathrm{pmol} \cdot \mathrm{L}^{-1}$ were associated with moderatesevere $\mathrm{PH}$ on echocardiography. Importantly, BNP levels did not correlate with parameters of left heart dysfunction, although left heart dysfunction was not a common finding in our patient population $(n=7)$. However, this study was not designed to evaluate BNP against other indirect measures of $\mathrm{PH}$, but instead against mortality. In severe ILD, elevated pulmonary vascular resistance strongly predicts mortality [4]. In earlier disease, routine $\mathrm{RHC}$ is neither realistic nor desirable. Thus, we evaluated the prognostic implications of pulmonary vascular stress as measured by indirect methods, including BNP. Elevated BNP concentrations have previously been associated with PH on RHC in an IPF population [19], supporting the concept that raised BNP reflects pulmonary vascular compromise. In our study, raised BNP was associated with markers of right heart dysfunction, suggesting that elevated BNP may be a marker of early pulmonary vascular impairment.

\section{Limitations of the study}

In this study we chose to study ILD in general, rather than an individual ILD subgroup, such as IPF. We have previously shown that elevated pulmonary vascular resistance measured at RHC strongly predicts rapid mortality across the ILD population [4] and so we hypothesised that other markers of pulmonary vascular disease may also be prognostic markers across ILD. It was, therefore, important to include the whole ILD population, rather than study a specific ILD subgroup. However, as in our earlier study, we considered it important to establish that our results were not dominated by a single ILD subgroup [4]. Thus, we analysed the data, excluding each diagnostic subgroup in turn (as the alternative strategy of examining each subgroup in isolation was precluded by small subgroup numbers). Results remain highly statistically significant with the exclusion of each diagnostic subgroup, indicating that no ILD subgroup had overly influenced our findings.

Our study was necessarily limited by its retrospective design and patient selection. A wide range of disease severity was evaluated. At the start of the study period, there was a focus on cases with clinical suspicion of $\mathrm{PH}$, but in the latter part of the study period, BNP was performed routinely on new referrals. We suggest that the resultant range of disease severity and suspicion of $\mathrm{PH}$ involvement reflects real-life clinical practice, and is a representative population in which to explore proof of concept outcome analyses. However, exact clinical utility with reference to unselected ILD cases cannot be extrapolated from our data.

The attempted construction of a staging system, by combining BNP and echocardiographic thresholds, was hampered by low subgroup numbers. Prospective larger studies with longer periods of observation are required to further delineate the relative importance of these prognostic markers alone and in combination, and before these markers can be widely used for prognostic staging in the ILD population.

\section{Conclusion}

Elevated BNP concentration and RVSP levels are linked to higher mortality across the ILD population, independent of the severity of the underlying lung fibrosis. Increased serum BNP concentration was the strongest predictor of overall mortality across ILD patients. $\mathrm{BNP} \geqslant 20 \mathrm{pmol} \cdot \mathrm{L}^{-1}$ and moderate to severe $\mathrm{PH}$ on echocardiography were associated with increased mortality. The link between these vascular parameters and mortality supports the concept that pulmonary vascular disease contributes to the final common pathway seen across ILD patients.

\section{STATEMENT OF INTEREST}

None declared.

\section{REFERENCES}

1 Nadrous HF, Pellikka PA, Krowka MJ, et al. The impact of pulmonary hypertension on survival in patients with idiopathic pulmonary fibrosis. Chest 2005; 128: Suppl. 6, 616S-617S.

2 Hamada K, Nagai S, Tanaka S, et al. Significance of pulmonary arterial pressure and diffusion capacity of the lung as prognosticator in patients with idiopathic pulmonary fibrosis. Chest 2007; 131: 650-656.

3 Lettieri CJ, Nathan SD, Barnett SD, et al. Prevalence and outcomes of pulmonary arterial hypertension in advanced idiopathic pulmonary fibrosis. Chest 2006; 129: 746-752.

4 Corte TJ, Wort SJ, Gatzoulis MA, et al. Pulmonary vascular resistance predicts early mortality in patients with diffuse fibrotic lung disease and suspected pulmonary hypertension. Thorax 2009; 64: 883-888.

5 Shorr AF, Helman DL, Davies DB, et al. Pulmonary hypertension in advanced sarcoidosis: epidemiology and clinical characteristics. Eur Respir J 2005; 25: 783-788.

6 Agarwal R, Gupta D, Verma JS, et al. Noninvasive estimation of clinically asymptomatic pulmonary hypertension in idiopathic pulmonary fibrosis. Indian J Chest Dis Allied Scis 2005; 47: 267-271.

7 Nathan SAS, Koch J, Barnett S, et al. Serial measures of pulmonary artery pressures in patients with idiopathic pulmonary fibrosis. Chest 2005; 128: 168 S.

8 Arcasoy SM, Christie JD, Ferrari VA, et al. Echocardiographic assessment of pulmonary hypertension in patients with advanced lung disease. Am J Respir Crit Care Med 2003; 167: 735-740.

9 Zisman DA LJ, Strieter RM, Saggar R, et al. Pulmonary arterial hypertension (PAH) is common in patients with idiopathic pulmonary fibrosis referred for lung transplantation. Am J Respir Crit Care Med 2005; 2: A123.

10 Gagermeier J DJ, Gibson K, Richards T, et al. Prevalence of secondary pulmonary hypertension in patients with idiopathic pulmonary fibrosis. Proc Am Thorac Soc 2005; 2: A205.

11 Yang SJ, Hoffman C, Mulligan K, et al. Pulmonary arterial hyperension in patients with idiopathic pulmonary fibrosis when listed for lung transplantation and at lung transplantation. Proc Am Thorac Soc 2006; 3: A369.

12 Nadrous HF, Pellikka PA, Krowka MJ, et al. Pulmonary hypertension in patients with idiopathic pulmonary fibrosis. Chest 2005; 128: 2393-2399.

13 Harari S, Simonneau G, De Juli E, et al. Prognostic value of pulmonary hypertension in patients with chronic interstitial lung disease referred for lung or heart-lung transplantation. J Heart Lung Transplant 1997; 16: 460-463. 
14 Mukoyama M, Nakao K, Hosoda K, et al. Brain natriuretic peptide as a novel cardiac hormone in humans. Evidence for an exquisite dual natriuretic peptide system, atrial natriuretic peptide and brain natriuretic peptide. J Clin Invest 1991; 87: 1402-1412.

15 Nagaya N, Nishikimi T, Okano $Y$, et al. Plasma brain natriuretic peptide levels increase in proportion to the extent of right ventricular dysfunction in pulmonary hypertension. J Am Coll Cardiol 1998; 31: 202-208.

16 Nootens M, Kaufmann E, Rector $\mathrm{T}$, et al. Neurohormonal activation in patients with right ventricular failure from pulmonary hypertension: relation to hemodynamic variables and endothelin levels. J Am Coll Cardiol 1995; 26: 1581-1585.

17 Leuchte HH, Holzapfel M, Baumgartner RA, et al. Clinical significance of brain natriuretic peptide in primary pulmonary hypertension. J Am Coll Cardiol 2004; 43: 764-770.

18 Leuchte HH, Baumgartner RA, Nounou ME, et al. Brain natriuretic peptide is a prognostic parameter in chronic lung disease. Am J Respir Crit Care Med 2006; 173: 744-750.

19 Leuchte $\mathrm{HH}$, Neurohr C, Baumgartner R, et al. Brain natriuretic peptide and exercise capacity in lung fibrosis and pulmonary hypertension. Am J Respir Crit Care Med 2004; 170: 360-365.

20 Song JW, Song JK, Kim DS. Echocardiography and brain natriuretic peptide as prognostic indicators in idiopathic pulmonary fibrosis. Respir Med 2009; 103: 180-186.

21 de Lemos JA, Gibson CM, Antman EM, et al. Abciximab and early adjunctive percutaneous coronary intervention are associated with improved ST-segment resolution after thrombolysis: Observations from the TIMI 14 Trial. Am Heart J 2001; 141: 592-598.

22 Logeart D, Thabut G, Jourdain P, et al. Predischarge B-type natriuretic peptide assay for identifying patients at high risk of readmission after decompensated heart failure. J Am Coll Cardiol 2004; 43: 635-641.

23 Kircher BJ, Himelman RB, Schiller NB. Noninvasive estimation of right atrial pressure from the inspiratory collapse of the inferior vena cava. Am J Cardiol 1990; 66: 493-496.

24 Currie PJ, Seward JB, Chan KL, et al. Continuous wave Doppler determination of right ventricular pressure: a simultaneous
Doppler-catheterization study in 127 patients. J Am Coll Cardiol 1985; 6: 750-756.

25 Macintyre N, Crapo RO, Viegi G, et al. Standardisation of the single-breath determination of carbon monoxide uptake in the lung. Eur Respir J 2005; 26: 720-735.

26 Miller MR, Hankinson J, Brusasco V, et al. Standardisation of spirometry. Eur Respir J 2005; 26: 319-338.

27 Wanger J, Clausen JL, Coates A, et al. Standardisation of the measurement of lung volumes. Eur Respir J 2005; 26: 511-522.

28 Gibson GJ. Standardised lung function testing. Eur Respir J 1993; 6 : 155-157.

29 Wells AU, Desai SR, Rubens MB, et al. Idiopathic pulmonary fibrosis: a composite physiologic index derived from disease extent observed by computed tomography. Am J Respir Crit Care Med 2003; 167: 962-969.

30 ATS statement: guidelines for the six-minute walk test. Am J Respir Crit Care Med 2002; 166: 111-117.

31 Pantelidis P, Fanning GC, Wells AU, et al. Analysis of tumor necrosis factor-alpha, lymphotoxin-alpha, tumor necrosis factor receptor II, and interleukin-6 polymorphisms in patients with idiopathic pulmonary fibrosis. Am J Respir Crit Care Med 2001; 163: 1432-1436.

32 Nagaya N, Nishikimi T, Uematsu M, et al. Plasma brain natriuretic peptide as a prognostic indicator in patients with primary pulmonary hypertension. Circulation 2000; 102: 865-870.

33 Souza R, Jardim C, Carvalho C, et al. The role of NT-proBNP as a prognostic marker in pulmonary hypertension. Chest 2006; 130: 1627.

34 Fijalkowska A, Kurzyna M, Torbicki A, et al. Serum N-terminal brain natriuretic peptide as a prognostic parameter in patients with pulmonary hypertension. Chest 2006; 129: 1313-1321.

35 Latsi PI, du Bois RM, Nicholson AG, et al. Fibrotic idiopathic interstitial pneumonia: the prognostic value of longitudinal functional trends. Am J Respir Crit Care Med 2003; 168: 531-537.

36 Perez-Padilla R, Salas J, Chapela R, et al. Mortality in Mexican patients with chronic pigeon breeder's lung compared with those with usual interstitial pneumonia. Am Rev Respir Dis 1993; 148: 49-53. 